\title{
Effects of ambient carbon monoxide on daily hospitalizations for cardiovascular disease: a time-stratified case-crossover study of 460,938 cases in Beijing, China from 2013 to 2017
}

Haibin $\mathrm{Li}^{1,2}$, Jingwei Wu${ }^{3}$, Anxin Wang ${ }^{4}$, Xia $\mathrm{Li}^{5}$, Songxi Chen ${ }^{6}$, Tianqi Wang ${ }^{1,7}$, Endawoke Amsalu ${ }^{1,2}$, Qi Gao ${ }^{1,2}$, Yanxia Luo ${ }^{1,2}$, Xinghua Yang ${ }^{1,2}$, Wei Wang ${ }^{8}$, Jin Guo ${ }^{9}$, Yuming Guo ${ }^{10}$ and Xiuhua Guo ${ }^{1,2^{*}}$ (D)

\begin{abstract}
Background: Evidence focused on exposure to ambient carbon monoxide (CO) and the risk of hospitalizations for cardiovascular diseases (CVD) is lacking in developing countries. This study aimed to examine the effect of CO exposure on hospitalizations for CVD in Beijing, China.

Methods: A total of 460,938 hospitalizations for cardiovascular diseases were obtained from electronic hospitalization summary reports from 2013 to 2017. A time-stratified case-crossover design was conducted to investigate the association between CO exposure and hospitalizations for total and cause-specific CVD, including coronary heart disease (CHD), atrial fibrillation (AF), and heart failure (HF). Stratified analysis was also conducted by age group (18-64 years and $\geq 65$ years) and sex.
\end{abstract}

Results: Linear exposure-response curves for the association between ambient $\mathrm{CO}$ exposure and hospitalizations for CVD was observed. Ambient CO was positively associated with hospitalizations for total CVD and CHD. However, the observed increased risk was not statistically significant for hospitalizations for AF and HF. The strongest effect of CO concentration was observed on the current- and previous-day of exposure (lag o-1 day). For a $1 \mathrm{mg} / \mathrm{m}^{3}$ increase in a 2-day moving average CO concentration, an increase of 2.8\% [95\% confidence interval (Cl): 2.2 to 3.3\%] and 3.0\% (95\% Cl: 2.4 to 3.6\%) in daily hospital admissions for CVD and CHD were estimated, respectively. This association was robust after adjusting for other copollutants and did not vary by age group and sex.

Conclusions: Ambient CO exposure increased the risk of hospitalizations for CVD, especially for CHD in Beijing. Further studies are warranted to explore the association between ambient $\mathrm{CO}$ and hospitalizations for AF and HF.

Keywords: Carbon monoxide, Hospitalizations, Cardiovascular disease

\footnotetext{
* Correspondence: statguo@ccmu.edu.cn

'Department of Epidemiology and Health Statistics, School of Public Health,

Capital Medical University, Beijing, China

${ }^{2}$ Beijing Municipal Key Laboratory of Clinical Epidemiology, Capital Medical

University, Beijing, China

Full list of author information is available at the end of the article
}

(c) The Author(s). 2018 Open Access This article is distributed under the terms of the Creative Commons Attribution 4.0 International License (http://creativecommons.org/licenses/by/4.0/), which permits unrestricted use, distribution, and reproduction in any medium, provided you give appropriate credit to the original author(s) and the source, provide a link to the Creative Commons license, and indicate if changes were made. The Creative Commons Public Domain Dedication waiver (http://creativecommons.org/publicdomain/zero/1.0/) applies to the data made available in this article, unless otherwise stated. 


\section{Introduction}

Cardiovascular disease (CVD) is a leading cause of morbidity and mortality worldwide [1]. In China, approximately 29.8 million deaths in rural areas and 26.5 million deaths in urban areas were caused by CVD in 2015 [2]. Meta-analysis and epidemiological studies have reported that air pollution increased the risk of morbidity and mortality due to CVD [3-7]. Recently, Liu and colleagues conducted a nationwide time-series analysis in 272 major cities in China and found that ambient carbon monoxide (CO) exposure caused a $1.1 \%$ (95\% confidence interval: 0.4 to $1.8 \%$ ) increase in the risk of cardiovascular disease mortality per $1 \mathrm{mg} / \mathrm{m}^{3}$ increment [7]. However, the adverse effects of ambient $\mathrm{CO}$ on hospital admissions for cardiovascular disease has not been well described and the results were inconsistent across studies [7-12]. For example, Koken, et al. reported a significant association between short-term exposure to ambient $\mathrm{CO}$ and hospitalizations for CVD among elderly individuals in Denver [8]. However, this association between ambient $\mathrm{CO}$ and hospitalizations for CVD outcomes was found to be statistically insignificant by the Myocardial Ischemia National Audit Project [12].

In many large cities such as Beijing, the capital of China, traffic-related pollution has become a serious environmental problem. The total number of motor vehicles on the road in Beijing was nearly 5.64 million in 2017. Approximately $80 \%$ of ambient CO was attributed to exhaust emissions from motor vehicles. Ambient $\mathrm{CO}$ is a colorless, odorless and nonirritating gas pollutant. The adverse health effects of ambient $\mathrm{CO}$ exposure on cardiovascular mortality has been reported in multi-city analyses in China $[7,13]$. To the best of our knowledge, only one multi-city study conducted in China examined the short-term effects of ambient CO on CVD hospital admissions [14]. This study showed that a $1 \mathrm{mg} / \mathrm{m}^{3}$ increase in CO concentrations was associated with a $4.4 \%$ increase in CVD hospital admissions [14]. However, the short-term effects of ambient $\mathrm{CO}$ exposure on cause-specific CVD hospitalizations in China remain unknown. Additionally, this association on the city-specific level has not comprehensively reported, especially in large cities, such as Beijing.

In this study, we aimed to examine the associations between ambient $\mathrm{CO}$ and total and cause-specific CVD hospital admissions in Beijing. We also investigated the robustness of this association after controlling for fine particulate matter, sulfur dioxide, nitrogen dioxide, and ozone. Stratified analyses by sex and age were further conducted to explore the associations in these susceptible subpopulations.

\section{Methods}

\section{Health outcome data}

CVD hospital admission records were extracted from the Beijing Municipal Commission of Health and Family Planning Information Center (http://www.phic.org.cn/) between Jan 1, 2013, and Dec 31, 2017. The geographic locations of hospitals in this study are shown in Fig. 1. From each hospital admission record, we extracted information on the patient's date of hospital admission, principal diagnosis, age, and sex. Cause-specific CVD hospitalizations were identified based on the primary diagnosis according to the following International Classification of Diseases, 10th Revision (ICD-10) codes: coronary heart disease (ICD-10: I20-I25, CHD), atrial

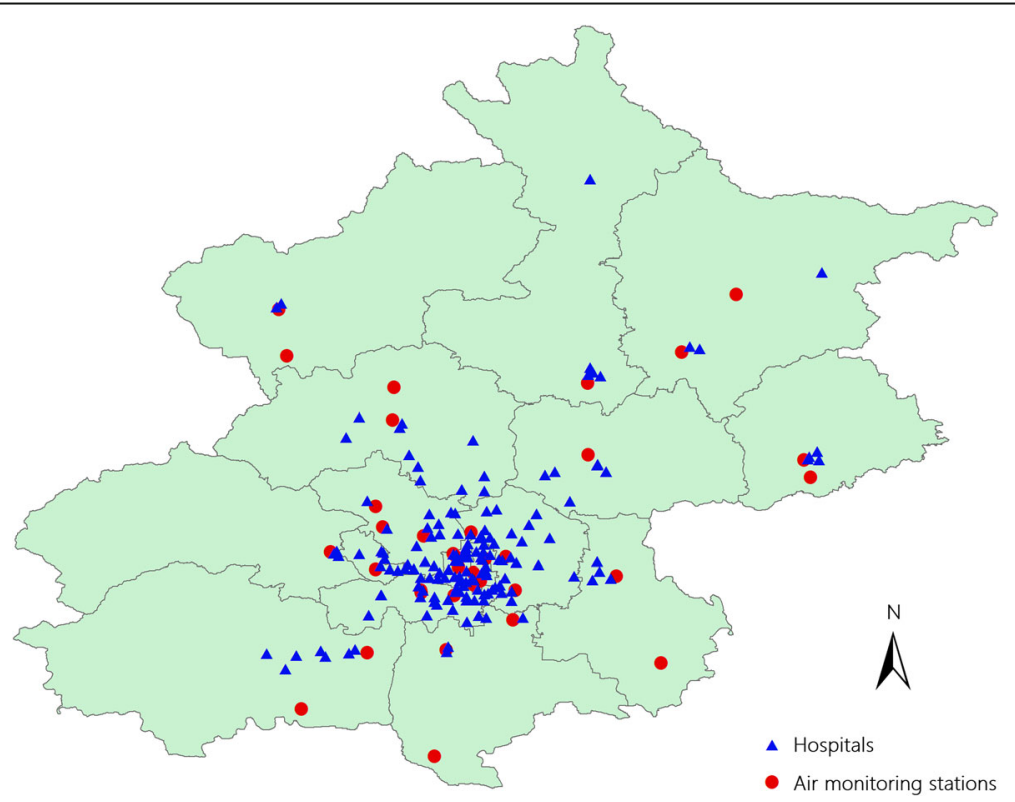

Fig. 1 The locations of the air quality monitoring stations and hospitals 
fibrillation (ICD-10: I48, AF) and heart failure (ICD-10: I50, HF). In this study, total CVD admissions were calculated as the sum of CHD, AF and HF. Because few hospital admissions for CVD under the age of 18 years were recorded; thus, these individuals were excluded from the current analysis.

The Institutional Review Board at the Capital Medical University approved the study's protocol (IRB00009511). Informed consent was waived as the data were typically used for administrative purposes. Only aggregated data was used for the current analysis.

\section{Air pollution and meteorological data}

We obtained air pollution data between Jan 1, 2013, and Dec 31, 2017, from the Beijing Municipal Environmental Protection Bureau (http://www.bjepb.gov.cn/), which provided hourly monitoring data from 35 fixed-site air quality monitoring stations covering nearly every district (county level) in Beijing. The locations of monitoring stations are also shown in Fig. 1. The 24-h average concentrations of five pollutants, including carbon monoxide (CO), particulate matter less than $2.5 \mu \mathrm{m}$ in aerodynamic diameter $\left(\mathrm{PM}_{2.5}\right)$, sulfur dioxide $\left(\mathrm{SO}_{2}\right)$, nitrogen dioxide $\left(\mathrm{NO}_{2}\right)$ and daily maximum 8 -h average ozone concentrations $\left(\mathrm{O}_{3}\right)$ were used in this study. Moreover, to adjust for the potential confounding effects of weather conditions, meteorological data including the daily mean temperature, mean air pressure, and mean relative humidity were extracted for the same study period from the China Meteorological Data Sharing Service System (https://data.cma.cn/en).

\section{Study design}

The case-crossover design $[15,16]$, which was first introduced by Maclure [17], is increasingly used in the literature to explore the short-term effects of air pollutant exposure on the risk of acute events $[12,18,19]$. In this study, a time-stratified case-crossover study design was used to compare each patient's ambient $\mathrm{CO}$ exposure on the day of hospital admission for CVD ("case" day) to exposure on 3 or 4 reference days occurring on the same day of week in the same calendar month and year ("control" days). With this design, each stratum consisted of one case on the case day and several references on the control days; thus, biases due to long-term time trends and seasonal variations can be avoided [20]. Additionally, since individual patients serve as their own controls, individual characteristics (such as age, sex, marital status, education, etc.) are also well controlled [15].

\section{Statistical analysis}

Conditional logistic regression is the standard statistical approach in the case-crossover analysis [21]. From statistical perspective, case-crossover design using a conditional logistic regression is a merely special case of time-series analysis $[16,22]$. Typically, a stratum variable will be defined by including one case and all other referents as if a matched case-control study. Thus, if there are relatively large number of referents for each case, or if there are multiple cases on the same day, the stratum data must be expanded and repeated as many times in order to be modelled by conditional logistic regression, which is computationally inefficient. To minimize computational complications, we applied a conditional Poisson regression model which has been proven to give equivalent estimates as the conditional logistic model but allowing for over-dispersion and auto-correlation [23]. Conditional Poisson regression model is increasingly used for case-crossover analysis in environmental epidemiology [19, 23-25].

As mentioned previously, we first defined a stratum variable as a combination of the year, month and day of week, which was used to match a case and controls by the day of the week in the same calendar month. This variable can be used to control for time-dependent confounders (e.g., long-term trend, seasonality). Additionally, we controlled for weather conditions by including 4-day moving average of temperature ( $\left.\operatorname{lag}_{0-3}\right)$, the same day of air pressure and relative humidity (lag o) as covariates for the model fit based on a prior study [18]. Considering that a nonlinear relationship had been shown between temperature, air pressure, relative humidity and hospitalizations for CVD in the previous studies $[7,19,26]$, a natural cubic spline with three degrees of freedom $(d f)$ was used for each weather condition variable. Public holidays (except on Saturdays and Sundays) were regarded as a binary variable (yes or no) and adjusted in the model [4]. Thus, in the current analysis, the conditional Poisson regression model has the form:

$$
\begin{aligned}
& Y_{t} \sim \operatorname{Poisson}\left(\mu_{t}\right) \\
& \log \left(\mu_{t}\right)=a+\beta C O_{(t, l)} \\
& +n s(\text { temperature }(t, l=0-3), d f=3) \\
& +n s\left(\operatorname{pressure}_{(t, l=0)}, d f=3\right) \\
& +n s\left(\text { relative_humidity }_{(t, l=0)}, d f=3\right) \\
& +\lambda \text { Stratum }_{t}+\text { vHoliday }_{t}
\end{aligned}
$$

where $Y_{t}$ is the observed daily CVD hospital admissions count on day t; $\mu_{t}$ is the expected daily CVD hospital admissions count on day $\mathrm{t} ;$ is the lag of the day; $\beta$ is the coefficient for $\mathrm{CO}$ concentration on different lag days; $n s(\ldots)$ is the natural cubic spline; $d f$ is the degrees of freedom; $\lambda$ is the coefficient for stratum that combines 
year, month and day of week; $v$ is the coefficient for public holidays.

We first conducted a single-pollutant model to estimate the linear effect of ambient CO on CVD hospital admissions using different lag patterns. The single-day effect of ambient $\mathrm{CO}$ was calculated on the same day ( $\operatorname{lag} 0$ ) and up to the previous 5 days (from $\operatorname{lag}_{1}$ to $\operatorname{lag}_{5}$ ). The cumulative delay effect was calculated as the moving average of concentrations from the same day to the previous 1 days $\left(\operatorname{lag}_{0-1}\right)$, to the previous 3 days (lag $0-3$ ) and to the previous 5 days (lag $0-5$ ). According to the previous studies $[7,10,27]$, the 2-day moving average concentrations of $\mathrm{CO}$ (lag ${ }_{0-1}$ ) often produced the largest estimate effects on CVD morbidity and mortality [7]; therefore, we mainly reported the estimates effect at lag $0_{-1}$. We further plotted exposure-response association curves using the nature cubic spline with three $d f$ for the concentrations of CO (lag 0-1) [13]. The nonlinear association was examined by the Wald-test [28].

We also performed multipollutant models as sensitivity analyses to evaluate the robustness of our results. To remove the impact of collinearity between $\mathrm{CO}$ and other air pollutants $\left(\mathrm{PM}_{2.5}, \mathrm{SO}_{2}, \mathrm{NO}_{2}, \mathrm{O}_{3}\right)$, principal component analysis (PCA) was used to establish the models [29]. We first substituted all original air pollutants by a composite latent variable (a linear combination of all air pollutants) through PCA, and then included this latent variable in conditional Poisson regression model. Meanwhile, the coefficient $\beta^{\prime}$ of this latent variable was transformed into the coefficient $\beta$ of the original air pollutants [30].

The potential effect modification on the association between ambient $\mathrm{CO}$ (lag $0_{-1}$ ) and hospital admission for CVD was examined. First, subgroup analyses stratified by demographic characteristics (age group: 18-64 and $\geq 65$ years; sex: male and female) were conducted in the single-pollutant model. A $\mathrm{Z}$ value was calculated to test the statistical significance of subgroups differences as follows: $\mathrm{Z}=\left(\beta_{1}-\beta_{2}\right) / \sqrt{S E_{1}^{2}+S E_{2}^{2}}$, where $\beta_{1}$ and $\beta_{2}$ were the effect estimates for the two categories (e.g., male and female) and $S E_{1}$ and $S E_{2}$ were their respective corresponding standard errors [11,31]. Finally, a $P$ value was obtained from the standard normal distribution based on the $Z$ value [31].

The relative risk (RR) was calculated from the conditional Poisson regression model $\left(\mathrm{RR}=e^{\beta}\right)$. We reported the percentage changes $(\mathrm{PC} \%=[\mathrm{RR}-1] \times 100 \%)$ in daily hospital admissions for CVD per $1 \mathrm{mg} / \mathrm{m}^{3}$ increase of $\mathrm{CO}$ concentrations and its corresponding 95\% confidence interval (CI). All analyses were performed using Stata 14 (StataCorp., College Station, Texas), with the "xtpoisson" command to fit the conditional Poisson regression, "mkspline" command to build the nature cubic spline, "pca" command to conduct PAC, and "testparm" commend to perform the Wald-test. $P$ value $<0.05$ was deemed statistically significant.

\section{Results}

We included 460,938 hospital admissions for CVD, including 378,090 CHD cases, 24,455 AF cases and 58,393 HF cases, during the 5-year study period in Beijing. Of those, $54.9 \%$ were males, and $37.6 \%$ were under 65 years of age. Table 1 shows the descriptive statistics of the daily hospital admissions (counts per day) for total and cause-specific CVD, air pollution concentrations, and weather conditions. On average, there were 252 hospital admissions for CVD per day, with a maximum of 749 admissions in a single day during the study period.

The daily 24-h mean CO concentration in Beijing was $1.2 \mathrm{mg} / \mathrm{m}^{3}$ (SD: 1.0 ; range: $0.0-8.0$ ). During the study period, the daily $24-\mathrm{h}$ mean pollution concentration was $76.9 \mu \mathrm{g} / \mathrm{m}^{3}$ for $\mathrm{PM}_{2.5}, 15.3 \mu \mathrm{g} / \mathrm{m}^{3}$ for $\mathrm{SO}_{2}$, and $49.7 \mu \mathrm{g} / \mathrm{m}^{3}$ for $\mathrm{NO}_{2}$, and the 8-h maximum mean concentration for $\mathrm{O}_{3}$ was $95.7 \mu \mathrm{g} / \mathrm{m}^{3}$. The daily mean ambient temperature was $13.9^{\circ} \mathrm{C}$, relative humidity was $24.4 \%$ and air pressure was $1016.7 \mathrm{hPa}$ (Table 1 ).

The pairwise correlation among different air pollution concentrations and weather conditions during the study period is provided in Table 2. There were strong positive to moderate correlations between $\mathrm{CO}$ and $\mathrm{PM}_{2.5}$ (Pearson's, $\left.r=0.830\right), \mathrm{NO}_{2}(r=0.820)$ as well as $\mathrm{SO}_{2}(r=0.670)$, but the correlation between $\mathrm{CO}$ and $\mathrm{O}_{3}$ was negative and weak $(r=-0.379)$. Additionally, the correlations between $\mathrm{CO}$ and each weather condition were relatively weak.

Fig. 2 shows the effects of $\mathrm{CO}$ exposure $\left(1 \mathrm{mg} / \mathrm{m}^{3}\right.$ increment) with varying lag patterns on the percentage change of daily hospital admission for CVD, CHD, AF and HF. The effect of ambient $\mathrm{CO}$ gradually decreased from lag 0 to lag ${ }_{5}$ day. We found that ambient $\mathrm{CO}$ was positively and significantly associated with the percentage change in daily hospital admissions for CVD at lag 0 and lag ${ }_{1}$ day, but negative and significant associations were observed at lag 4 and lag ${ }_{5}$ day. The largest effect was observed on lag $0_{-1}$ day. Therefore, the following analyses only focused on the cumulative delay effects of $\mathrm{CO}$ on lag $0-1$ day. The lag patterns for $\mathrm{CHD}$ were consistent with CVD. These associations between $\mathrm{CO}$ exposure and $\mathrm{AF}$ as well as HF, however, were not significantly detected on any lag day (all $P>0.05$ ).

Figure 3 shows the exposure-response association curve between ambient $\mathrm{CO}$ concentrations on lag $0-1$ day and daily hospitalizations for total and cause-specific CVD. We did not find any apparent nonlinear exposure-response relationships for daily hospitalization for CVD (Wald $X^{2}=0.01, P$ for nonlinearity $=0.99$ ), CHD (Wald $\chi^{2}=0.61, P_{\text {for nonlinearity }}=0.74$ ), AF (Wald $\chi^{2}=0.06$, 
Table 1 Descriptive statistics for the daily hospital admissions for total and cause-specific cardiovascular disease, air pollution concentrations, and weather conditions in Beijing, 2013-2017

\begin{tabular}{|c|c|c|c|c|c|c|c|}
\hline & Mean & SD & Minimum & $P_{25}$ & Median & $P_{75}$ & Maximum \\
\hline \multicolumn{8}{|c|}{ Annual-average daily hospital admission } \\
\hline Cardiovascular disease & 252 & 165 & 9 & 106 & 192 & 405 & 749 \\
\hline Coronary heart disease & 207 & 142 & 2 & 77 & 159 & 340 & 632 \\
\hline Atrial fibrillation & 13 & 11 & 0 & 4 & 10 & 22 & 53 \\
\hline Heart failure & 32 & 16 & 0 & 20 & 29 & 43 & 90 \\
\hline \multicolumn{8}{|c|}{ Annual-average $\mathrm{CO}$ concentrations, $\mathrm{mg} / \mathrm{m}^{3}$} \\
\hline & 1.2 & 1.0 & 0.0 & 0.6 & 0.9 & 1.4 & 8.0 \\
\hline \multicolumn{8}{|c|}{ Annual-average pollution concentration $\left(\mu \mathrm{g} / \mathrm{m}^{3}\right)$} \\
\hline $\mathrm{PM}_{2.5}$ & 76.9 & 66.4 & 0.0 & 30.0 & 59.0 & 102.0 & 477.0 \\
\hline $\mathrm{SO}_{2}$ & 15.3 & 18.3 & 0.0 & 4.0 & 8.0 & 19.0 & 133.0 \\
\hline $\mathrm{NO}_{2}$ & 49.7 & 23.3 & 0.0 & 34.0 & 44.0 & 61.0 & 155.0 \\
\hline $\mathrm{O}_{3}$ & 95.7 & 63.0 & 0.0 & 49.0 & 80.8 & 136.0 & 366.7 \\
\hline \multicolumn{8}{|c|}{ Annual-average weather conditions } \\
\hline Mean temperature, ${ }^{\circ} \mathrm{C}$ & 13.9 & 10.9 & -14.1 & 3.1 & 15.3 & 23.9 & 32.6 \\
\hline Relative humidity, \% & 24.4 & 26.7 & 1.1 & 5.2 & 7.5 & 43.4 & 95.3 \\
\hline Air pressure, $\mathrm{hPa}$ & 1016.7 & 10.3 & 994.1 & 1008.0 & 1016.5 & 1025.3 & 1044.4 \\
\hline
\end{tabular}

$P_{25}$ 25th percentile, $P_{75}$ 75th percentile, $\mathrm{CO}$ carbon monoxide, $\mathrm{PM}_{2.5}$ particulate matter with aerodynamic diameter less than $2.5 \mu \mathrm{m}, \mathrm{SO}_{2}$ sulfur dioxide, $\mathrm{NO}_{2}$ nitrogen dioxide, $\mathrm{O}_{3}$ ozone

$P$ for nonlinearity $=0.97)$ or HF (Wald $X^{2}=3.05, P$ for nonlinearity $=0.21$ ).

Table 3 shows the cumulative delay effects (lag $0-1$ day) of $\mathrm{CO}$ concentrations on daily hospital admissions for total and cause-specific CVD. In the single pollutant model, for a $1 \mathrm{mg} / \mathrm{m}^{3}$ increase in the 2-day moving average $\mathrm{CO}$ concentrations (lag $0-1$ ), we observed significant increases of $2.8 \%$ (95\% CI: 2.2 to $3.3 \%$ ) in the daily hospital admission for CVD, 3.0\% (95\% CI: 2.4 to 3.6\%) for CHD, $1.4 \%$ (95\% CI: -1.4 to $4.2 \%$ ) for AF and $1.2 \%(-0.4$ to $2.7 \%$ ) for HF. In the multipollutant models where copollutants were adjusted by PCA, the significant associations observed in the single-pollutant models weakened but remained significant for CVD and CHD. Additionally, a week association was observed between ambient $\mathrm{CO}$ and hospital admissions for AF.
Figure 4 displays the associations between $\mathrm{CO}$ concentrations (lag 0-1 day) and hospital admission for total and cause-specific CVD, stratified by age group, and sex. No effect modifications were found to be significant (all $P_{\text {for heterogeneity }}>0.05$ ).

\section{Discussion}

In the present study, we used a time-stratified casecrossover design with conditional Poisson model to investigate the associations of ambient $\mathrm{CO}$ and hospitalizations for CVD in Beijing from 2013 to 2017. We found that short-term exposure to ambient $\mathrm{CO}$ was significantly associated with an increased risk of hospital admissions for CVD and CHD, but not for AF and HF. The largest estimate effects were observed on the lag $0-1$ day. Our

Table 2 Pearson correlation coefficients between air pollution concentrations and weather conditions in Beijing, 2013-2017

\begin{tabular}{|c|c|c|c|c|c|c|c|}
\hline & $\mathrm{CO}$ & $\mathrm{PM}_{2.5}$ & $\mathrm{SO}_{2}$ & $\mathrm{NO}_{2}$ & $\mathrm{O}_{3}$ & Temperature & Relative humidity \\
\hline $\mathrm{CO}$ & 1.000 & & & & & & \\
\hline $\mathrm{PM}_{2.5}$ & $0.830^{*}$ & 1.000 & & & & & \\
\hline $\mathrm{SO}_{2}$ & $0.670^{*}$ & $0.562^{*}$ & 1.000 & & & & \\
\hline $\mathrm{NO}_{2}$ & $0.820^{*}$ & $0.786^{*}$ & $0.633^{*}$ & 1.000 & & & \\
\hline $\mathrm{O}_{3}$ & $-0.379^{*}$ & $-0.149^{*}$ & $-0.338^{*}$ & $-0.383^{*}$ & 1.000 & & \\
\hline Temperature & $-0.398^{*}$ & $-0.183^{*}$ & $-0.488^{*}$ & $-0.354^{*}$ & $0.768^{*}$ & 1.000 & \\
\hline Relative humidity & -0.028 & -0.015 & $-0.277^{*}$ & -0.017 & 0.029 & $0.135^{*}$ & 1.000 \\
\hline Air pressure & $0.246^{*}$ & $0.061^{*}$ & $0.316^{*}$ & $0.221^{*}$ & $-0.691^{*}$ & $-0.875^{*}$ & $-0.090^{*}$ \\
\hline
\end{tabular}

* $P<0.001$

$\mathrm{CO}$ carbon monoxide, $\mathrm{PM}_{2.5}$ particulate matter with aerodynamic diameter less than $2.5 \mu \mathrm{m}, \mathrm{SO}_{2}$ sulfur dioxide, $\mathrm{NO}_{2}$ nitrogen dioxide, $\mathrm{O}_{3}$ ozone 


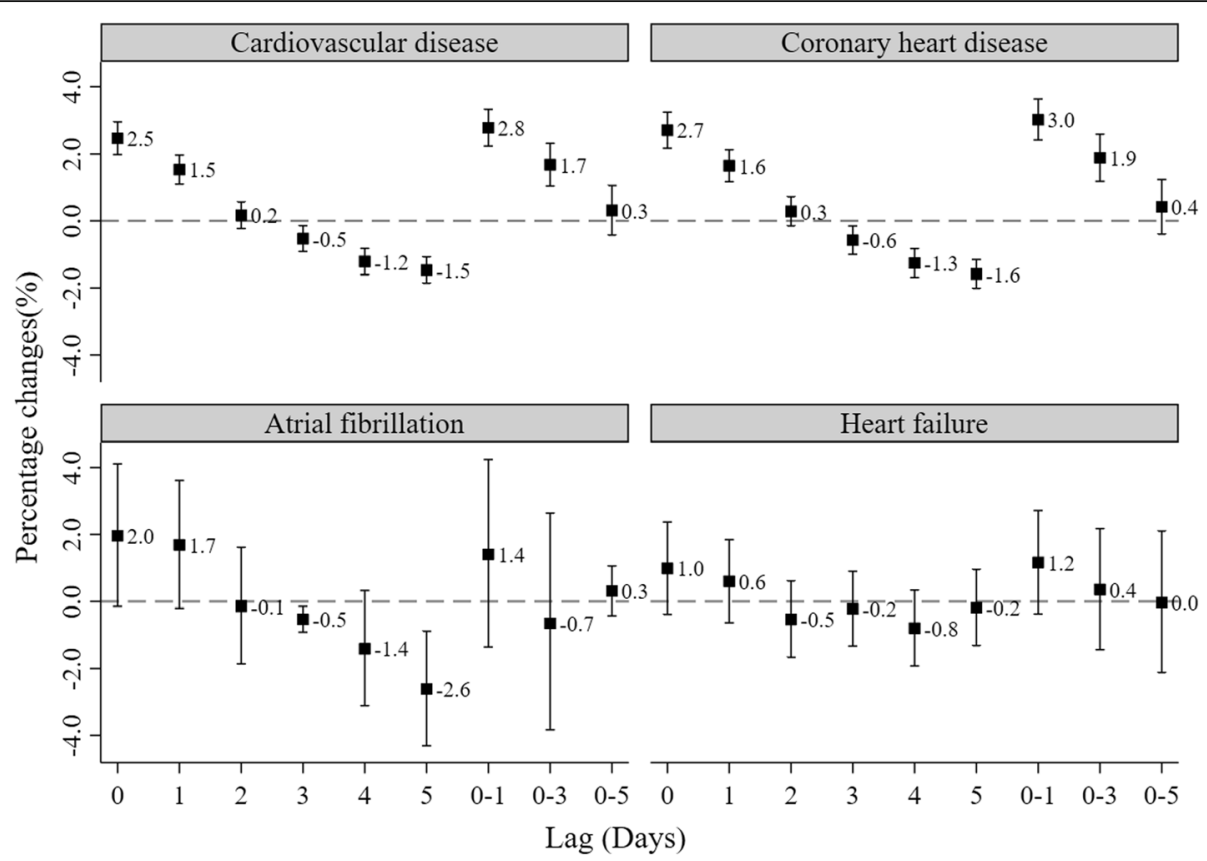

Fig. 2 Percentage change with 95\% confidence interval of hospital admissions for total and cause-special cardiovascular disease associated with a $1 \mathrm{mg} / \mathrm{m}^{3}$ increase in daily CO concentrations with varying lag patterns. Data are percentage changes (\%) with $95 \%$ confidence intervals. Lag $0=$ current day. $\operatorname{Lag}_{1}=$ previous 1 day. Lag $_{2}=$ previous 2 days. $\operatorname{Lag}_{3}=$ previous 3 days. $\operatorname{Lag}_{4}=$ previous 4 days. Lag $_{5}=$ previous 5 days. Lag $_{0-1}=2$-days moving average of lag $0-\operatorname{lag}_{1}$. Lag 0-3 $=4$-days moving average of $\operatorname{lag}_{0}-\operatorname{lag}_{4}$. Lag $0-5=6$-days moving average of lag $0-\operatorname{lag}_{5}$
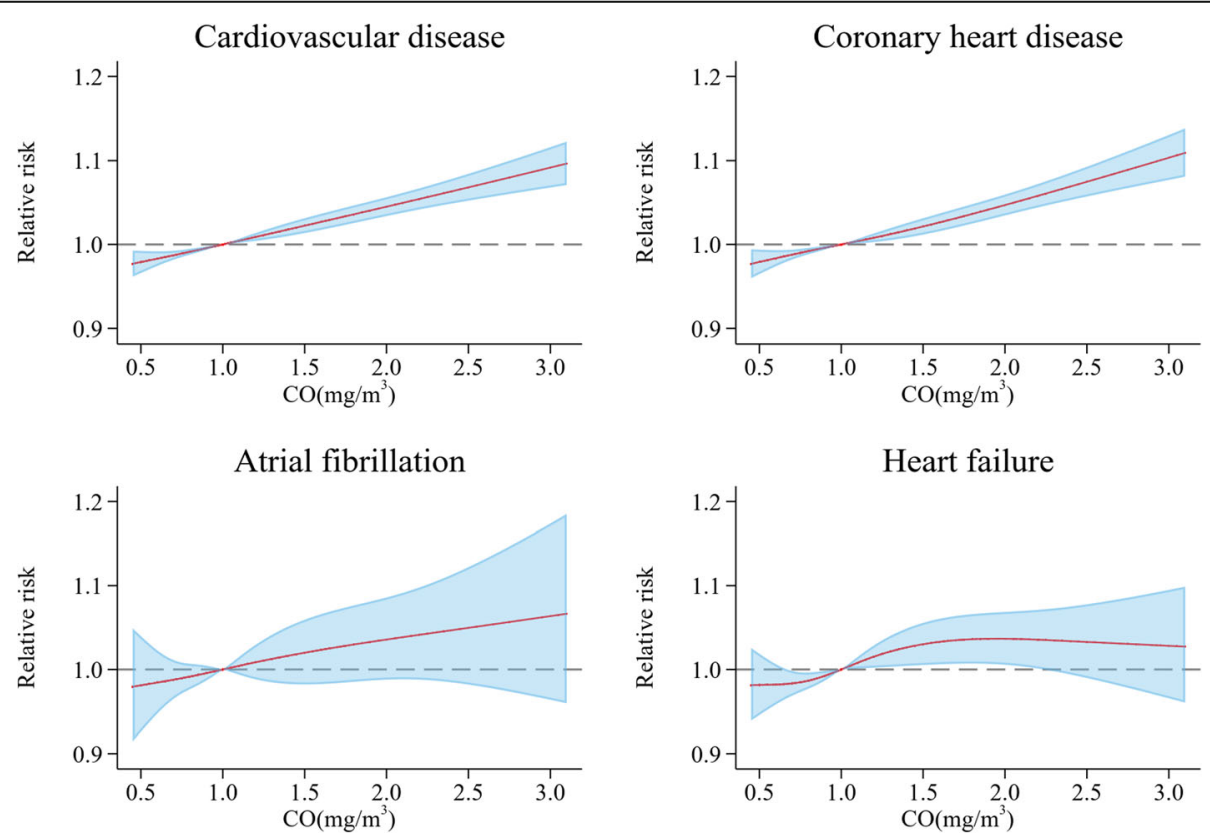

Fig. 3 Exposure-response relationship curves for the association between hospital admissions for total and cause-special cardiovascular disease

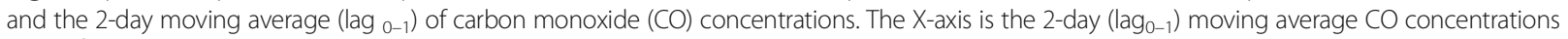
$\left(\mathrm{mg} / \mathrm{m}^{3}\right)$ truncated for the 5-95\% percentiles of the distribution concentrations in the figure. The $\mathrm{Y}$-axis is the relative risk (RR), after adjusting for temperature, relative humidity, air pressure, public holidays and long-term trends as well as seasonality. It is shown by the red solid line, and the blue shadow represent the $95 \%$ confidence interval 
Table 3 Percentage changes in daily hospital admission for total and cause-specific cardiovascular disease per $1 \mathrm{mg} / \mathrm{m}^{3}$ increase in 2-day moving average (lag $0-1$ ) concentration of carbon monoxide (CO), with and without adjustment of co-pollutants

\begin{tabular}{lll}
\hline & \multicolumn{2}{l}{ Percentage changes (\%) and 95\% confidence intervals } \\
\cline { 2 - 3 } & Single pollutant model ${ }^{a}$ & Multipollutant models ${ }^{\text {b }}$ \\
\hline Cardiovascular disease & $2.8(2.2$ to 3.3$)$ & $0.7(0.5$ to 0.9$)$ \\
Coronary heart disease & $3.0(2.4$ to 3.6$)$ & $0.8(0.6$ to 1.0$)$ \\
Atrial fibrillation & $1.4(-1.4$ to 4.2$)$ & $0.8(0.1$ to 1.5$)$ \\
Heart failure & $1.2(-0.4$ to 2.7$)$ & $0.2(-0.3$ to 0.7$)$ \\
\hline
\end{tabular}

${ }^{a}$ Without adjustment of co-pollutants

${ }^{\mathrm{b}}$ Adjustment of co-pollutants by principal component analysis

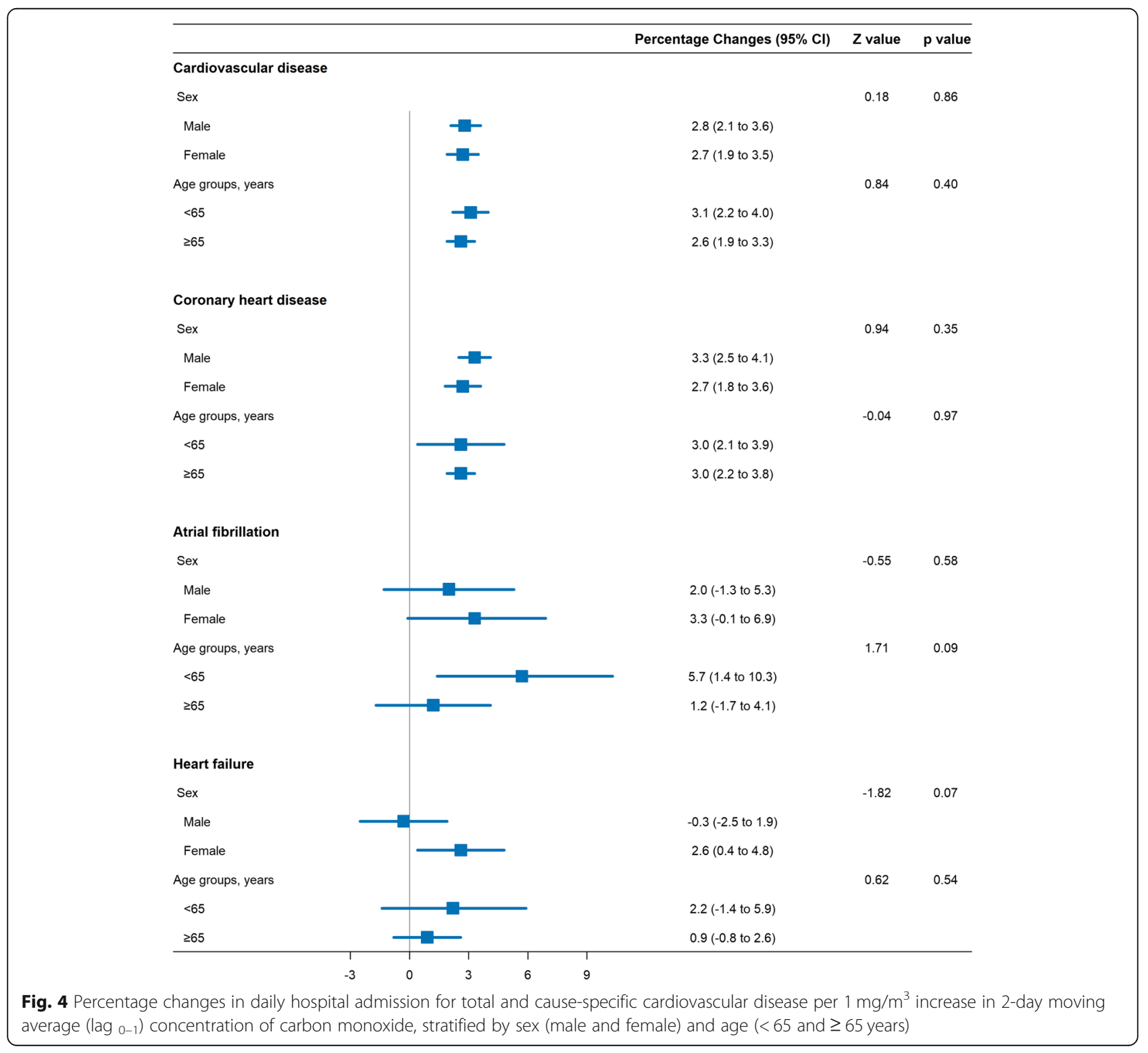


findings were robust after controlling for other pollutants in the multipollutant models.

Increasingly, scientific evidence has indicated that outdoor $\mathrm{CO}$ exposure is related to CVD morbidity and mortality [5-7, 10, 32-34]. For example, a multisite time-series study conducted by Bell, et al. found that a 1 $\mathrm{mg} / \mathrm{m}^{3}$ increase in the same-day daily 1 -h maximum $\mathrm{CO}$ was associated with a $1.0 \%$ (95\% CI: 0.8 to $1.1 \%$ ) increase in the risk of CVD admissions in 126 United States urban counties from 1999 to 2005 [10]. Barnett, et al. conducted a case-crossover study in seven Australian and New Zealand cities and combined the estimates across these cities using a random-effects meta-analysis. They found that a $0.9 \mathrm{mg} / \mathrm{m}^{3}$ increase in $\mathrm{CO}$ significantly increased the risk of hospital admissions for cardiovascular disease and ischemic heart disease by 2.2\% (95\% CI: 0.9 to $3.8 \%$ ) and $2.3 \%$ (95\% CI: 0.9 to $3.4 \%)$, respectively, in the elderly [33]. A study conducted in Arak, Iran reported that a $1 \mathrm{mg} / \mathrm{m}^{3}$ increase in $\mathrm{CO}$ concentrations on the same day was significantly associated with a $9.4 \%$ (95\% CI: 5.1 to $14.0 \%)$ increase in total cardiovascular hospital admissions [5]. Additionally, the impact of ambient $\mathrm{CO}$ on cardiovascular outcomes was attenuated after controlling for other pollutants. For example, a study performed in Valencia, Spain showed that ambient $\mathrm{CO}$ was significantly related to emergency cardiovascular admissions in a single pollutant model, but this association was dismissed after adjusting for $\mathrm{SO}_{2}$ [32]. Similarly, in the Bell, et al' study, this association was attenuated after adjusting with same-day $\mathrm{NO}_{2}$ [10]. To reduce the collinearity between $\mathrm{CO}$ and other pollutants, principle component analysis was conducted in multipollutant models. PCA is a multivariate method and has been applied in various multipollutant studies. Our current findings were consistent with those of previous studies exploring the association between $\mathrm{CO}$ exposure and the risk of hospital admissions for CVD after adjusting for $\mathrm{PM}_{2.5}, \mathrm{NO}_{2}, \mathrm{SO}_{2}$ and $\mathrm{O}_{3}[7,14]$.

In China, urbanization and economic development have greatly increased, especially in large cities such as Beijing and Shanghai. Gaseous air pollution $\left(\mathrm{CO}, \mathrm{SO}_{2}, \mathrm{O}_{3}\right.$, and $\mathrm{NO}_{2}$ ) has become a serious environmental problem. Ambient $\mathrm{CO}$ is primarily produced by incomplete combustion of carbon-containing fuels. The major source of $\mathrm{CO}$ in Beijing is generated from vehicle emissions. However, the adverse health effects of $\mathrm{CO}$ exposure on cardiovascular hospital admissions is understudied in China. Our findings were supported by a recent multicity analysis conducted in 14 large Chinese cities that reported a $0.8 \mathrm{mg} / \mathrm{m}^{3}$ increase in $\mathrm{CO}$ concentrations on lag ${ }_{2}$ day was significantly associated with a $1.1 \%$ (95\% CI: 0.4 to $1.8 \%$ ) increase in acute myocardial infarction admissions [35]. Moreover, associations between ambient $\mathrm{CO}$ and cardiovascular mortality had further been confirmed in a nationwide time-series analysis in 272 cities in China [7] and in the China Air Pollution and Health Effects Study (CAPES) [13]. Our results were consistent with previous studies performed in different Chinese cities [7, 13, 14, 35] that reported a significant $\mathrm{CO}$ exposure effect on lag ${ }_{0}$ and lag ${ }_{1}$ day, and a maximum $\mathrm{CO}$ exposure effect on lag ${ }_{0-1}$ day. Another recent study conducted in Beijing showed similar findings compared to our results [36]. Notably, a negative and significant association between $\mathrm{CO}$ exposure and hospitalizations for CVD or CHD was observed at lag ${ }_{4}$ and lag 5 day, which indicated a presence of "harvesting effect" in the current analysis. Similarly, a time-series study conducted in Beijing in 2009-2010 also found that ambient CO had a negative effect on CVD mortality at lag ${ }_{3}$ and lag ${ }_{4}$ day [30], which was consistent with what we observed in the current study.

The exposure-response relationship was approximately linear and there was no noticeable threshold effect below which $\mathrm{CO}$ exposure had no effects on cardiovascular hospitalizations in the current analysis, which was in accordance with other findings in previous studies [7, 13]. However, a multicity study in the 26 largest cities in China showed a negative effect of $\mathrm{CO}$ exposure on total CVD admissions observed below $1 \mathrm{mg} / \mathrm{m}^{3} \mathrm{CO}$ concentrations [14], which was also observed in our study. Therefore, further studies are necessary to explore the exposure-response relationship curve between $\mathrm{CO}$ levels and cardiovascular admissions.

We also found that the association between short-term $\mathrm{CO}$ exposure and hospital admissions varied by cause-specific CVD. The adverse effect was obvious and robust for daily hospitalizations for CHD, but not for AF or HF. Given the distinct differences in the underlying mechanisms through which that $\mathrm{CO}$ exposure triggers $\mathrm{CHD}$ compared with AF and $\mathrm{HF}[12,37,38]$, the impact of $\mathrm{CO}$ exposure on hospitalizations for cause-specific CVD could be substantially different. A previous meta-analysis that included only two prior studies suggested that $\mathrm{CO}$ pollutants were associated with an increased risk of AF [39]. The two prior studies used in the meta-analysis were conducted in the USA [40] and the UK [12]. The differences between China and these western countries in $\mathrm{CO}$ pollutants levels, weather conditions, and individual characteristics may partially explain the different adverse effects of ambient $\mathrm{CO}$ on hospitalization for AF. Additionally, a systematic review and meta-analysis with 35 high-quality studies demonstrated a 3.5\% (95\% CI: 2.5 to $4.5 \%$ ) increase in hospitalizations or mortality for HF per $1 \mathrm{mg} / \mathrm{m}^{3}$ increment in CO concentrations [41]. However, none of those 35 studies included in the meta-analysis were conducted in China's major cities [41]; thus the effects of $\mathrm{CO}$ pollution on hospitalizations for HF in China are less well- described [42]. Moreover, the prevalence of $\mathrm{AF}$ and HF in the Chinese population is considerably low. 
According to the China Multicenter Collaborative Study on Cardiovascular Epidemiology, the estimated prevalence of AF and HF in China is 1.0\% [43] and 0.9\% [44], respectively. In our current analysis, we observed a relatively small annual-average daily count for hospital admission due to AF and HF is very small (Mean: 13 for AF and 32 for HF). Thus, we might not have enough statistical power to elucidate a significant association between ambient $\mathrm{CO}$ and hospital admissions for AF or HF. Nevertheless, the exposure-response curves showed that high ambient $\mathrm{CO}$ exposure increased the risk of hospital admissions for AF and HF despite the statistical insignificance.

Identifying subpopulations who are the most susceptible is critically important for policy-maker to promote a targeted reduction in ambient CO [45]. A few studies suggested that females and elderly people were vulnerable to $\mathrm{CO}$ pollution-induced cardiovascular risk compared with males and younger people [11,46-48]. However, we did not find any differences in these effects when stratified by sex and age, implying that there is no convincing evidence for susceptible subgroups for the adverse $\mathrm{CO}$ exposure effects in China. This was consistent with previous epidemiological studies conducted in China [7, 42, 49] and UK [12]. Further studies are still warranted to evaluate whether sex and age are effect modifiers in the association between ambient $\mathrm{CO}$ and cardiovascular outcomes.

As previously shown, inhaled $\mathrm{CO}$ can bind to hemoglobin and form carboxyhemoglobin which decreases the oxygen-carrying capacity of hemoglobin and causes cellular hypoxia [50]. However, the concentration of ambient $\mathrm{CO}$ is considered too low to induce the toxic effects of CO [51]. Several plausible biological mechanisms underlying the association between low concentrations of ambient $\mathrm{CO}$ with CVD have been proposed, including cardiac dysfunction [52, 53], systemic inflammation [54, 55], oxidative stress [56, 57], and thrombotic reaction [55]. Both animal models and population-based cohort studies have demonstrated the cardiotoxicity of $\mathrm{CO}[48,52,53]$. A recent longitudinal study confirmed that high-sensitivity C-reactive protein increased with short-term exposure to $\mathrm{CO}$ among 61 patients with cardiovascular disease [55]. Fibrinogen and D-dimer significantly also increased with ambient $\mathrm{CO}$ exposure, and these biomarkers are related to thrombotic reactions $[54,55]$. Overall, the scientific evidence supports that ambient $\mathrm{CO}$ exposure is associated with cardiovascular risk.

Our study had several strengths. First, cardiovascular hospital admission data were obtained from an established monitoring system in Beijing; thus, misclassifications in cardiovascular outcomes were less likely to occur. Second, we explored the potential association between ambient $\mathrm{CO}$ and cause-specific CVD admissions. However, the limitations of our study also need to be noted. Similar to other studies exploring the impact of air pollutants on health outcomes, we need to carefully interpret and infer the cause-effect relationship between carbon monoxide exposure and hospitalizations for CVD due to the ecological design of the present study. We also used ambient $\mathrm{CO}$ data aggregated from fixed-site air quality monitoring stations to represent individual-level exposure, so measurement bias may exist.

\section{Conclusions}

Our findings have elucidated that short-term exposure to ambient CO significantly increased the risk of hospitalizations for total CVD, especially for CHD, in Beijing. Further study is necessary to identify the relationship between ambient $\mathrm{CO}$ and hospital admissions for AF and HF.

\section{Abbreviations}

AF: Atrial fibrillation; CHD: Coronary heart disease; CO: Carbon monoxide; CVD: Cardiovascular disease; HF: Heart failure; $\mathrm{NO}_{2}$ : Nitrogen dioxide; $\mathrm{O}_{3}$ : Ozone; PC: Percentage changes; $\mathrm{PM}_{25}$ : Particulate matter with aerodynamic diameter less than $2.5 \mu \mathrm{m}$; RR: Relative risk; $\mathrm{SO}_{2}$ : Sulfur dioxide

\section{Acknowledgements}

We acknowledge the Beijing Public Health Information Centre, Beijing Municipal Environmental Protection Bureau and China Meteorological Data Sharing Service System for providing above data.

\section{Funding}

This study was supported by the Program of Natural Science Fund of China (No. 81773512) and National Key Basic Research Project of China (No. 2016YFC0207705).

\section{Availability of data and materials}

The datasets during and/or analyzed during the current study are available from the corresponding author on reasonable request.

\section{Authors' contributions}

HL designed and wrote the manuscript. TQ applied the health data. HL, AW, $Y L$ and $E A$ analyzed the data. $H L, G Q$ and $X Y$ prepared the manuscript. JW, $X \mathrm{~L}$, and $\mathrm{SC}$ edited and improved the manuscript. $\mathrm{XG}$ and $\mathrm{WW}$ supervised and reviewed the manuscript. JG and YG participated in the discussion and improved the manuscript. All the authors reviewed the manuscript and approved the final version.

\section{Ethics approval and consent to participate}

Informed consent was not required as the data was typically used foradministrativ purposes. Only aggregated data was used for current analysis.

\section{Consent for publication}

Not applicable.

\section{Competing interests}

The authors declare that they have no actual or potential competing financial interests.

\section{Publisher's Note}

Springer Nature remains neutral with regard to jurisdictional claims in published maps and institutional affiliations.

\section{Author details}

${ }^{1}$ Department of Epidemiology and Health Statistics, School of Public Health, Capital Medical University, Beijing, China. ${ }^{2}$ Beijing Municipal Key Laboratory of Clinical Epidemiology, Capital Medical University, Beijing, China.

${ }^{3}$ Department of Epidemiology and Biostatistics, College of Public Health, Temple University, Philadelphia, USA. ${ }^{4}$ Department of Neurosurgery, Beijing Tiantan Hospital, Capital Medical University, Beijing, China. ${ }^{5}$ Department of 
Mathematics and Statistics, La Trobe University, Melbourne, VIC, Australia. ${ }^{6}$ School of Mathematical Sciences and Center for Statistical Science, Peking University, Beijing, China. ${ }^{7}$ Beijing Municipal Commission of Health and Family Planning Information Center, Beijing, China. ${ }^{8} \mathrm{Global}$ Health and Genomics, School of Medical Sciences and Health, Edith Cowan University, Perth, WA, Australia. ${ }^{9}$ Guanghua Group Pty Ltd, Melbourne, VIC, Australia. ${ }^{10}$ Department of Epidemiology and Preventive Medicine, School of Public Health and Preventive Medicine, Monash University, Melbourne, VIC, Australia.

Received: 9 August 2018 Accepted: 13 November 2018 Published online: 26 November 2018

\section{References}

1. Roth GA, Huffman MD, Moran AE, Feigin V, Mensah GA, Naghavi M, Murray CJ. Global and regional patterns in cardiovascular mortality from 1990 to 2013. Circulation. 2015;132(17):1667-78.

2. Chen WW, Gao RL, Liu LS, Zhu ML, Wang W, Wang YJ, Wu ZS, Li HJ, Gu DF, Yang YJ, et al. China cardiovascular diseases report 2015: a summary. J Geriatr Cardiol. 2017;14(1):1-10.

3. Shah AS, Lee KK, McAllister DA, Hunter A, Nair H, Whiteley W, Langrish JP, Newby DE, Mills NL. Short term exposure to air pollution and stroke: systematic review and meta-analysis. BMJ. 2015;350:h1295.

4. Xu Q, Wang S, Guo Y, Wang C, Huang F, Li X, Gao Q, Wu L, Tao L, Guo J. Acute exposure to fine particulate matter and cardiovascular hospital emergency room visits in Beijing, China. Environ Pollut. 2016;220(Pt A):317.

5. Vahedian M, Khanjani N, Mirzaee M, Koolivand A. Ambient air pollution and daily hospital admissions for cardiovascular diseases in Arak, Iran. ARYA Atheroscler. 2017;13(3):117-34

6. Cohen AJ, Brauer M, Burnett R, Anderson HR, Frostad J, Estep K, Balakrishnan K, Brunekreef B, Dandona L, Dandona R, et al. Estimates and 25-year trends of the global burden of disease attributable to ambient air pollution: an analysis of data from the global burden of diseases study 2015. Lancet. 2017;389(10082):1907-18.

7. Liu C, Yin P, Chen R, Meng X, Wang L, Niu Y, Lin Z, Liu Y, Liu J, Qi J, et al. Ambient carbon monoxide and cardiovascular mortality: a nationwide timeseries analysis in 272 cities in China. Lancet Planet Health. 2018;2(1):e12-8.

8. Koken PJ, Piver WT, Ye F, Elixhauser A, Olsen LM, Portier CJ. Temperature, air pollution, and hospitalization for cardiovascular diseases among elderly people in Denver. Environ Health Perspect. 2003;111(10):1312-7.

9. Chen TM, Gokhale J, Shofer S, Kuschner WG. Outdoor air pollution: nitrogen dioxide, sulfur dioxide, and carbon monoxide health effects. Am J Med Sci. 2007:333(4):249-56.

10. Bell ML, Peng RD, Dominici F, Samet JM. Emergency hospital admissions for cardiovascular diseases and ambient levels of carbon monoxide: results for 126 United States urban counties, 1999-2005. Circulation. 2009;120(11):949-55.

11. Tian L, Qiu H, Pun VC, Ho KF, Chan CS, Yu IT. Carbon monoxide and stroke: a time series study of ambient air pollution and emergency hospitalizations. Int J Cardiol. 2015;201:4-9.

12. Milojevic A, Wilkinson P, Armstrong B, Bhaskaran K, Smeeth L, Hajat S. Shortterm effects of air pollution on a range of cardiovascular events in England and Wales: case-crossover analysis of the MINAP database, hospital admissions and mortality. Heart. 2014;100(14):1093-8.

13. Chen R, Pan G, Zhang Y, Xu Q, Zeng G, Xu X, Chen B, Kan H. Ambient carbon monoxide and daily mortality in three Chinese cities: the China air pollution and health effects study (CAPES). Sci Total Environ. 2011;409(23): 4923-8.

14. Liu H, Tian Y, Xiang X, Li M, Wu Y, Cao Y, Juan J, Song J, Wu T, Hu Y Association of short-term exposure to ambient carbon monoxide with hospital admissions in China. Sci Rep. 2018;8(1):13336.

15. Janes H, Sheppard L, Lumley T. Case-crossover analyses of air pollution exposure data - referent selection strategies and their implications for bias. Epidemiology. 2005;16(6):717-26.

16. Lu Y, Zeger SL. On the equivalence of case-crossover and time series methods in environmental epidemiology. Biostatistics. 2007:8(2):337-44.

17. Maclure M. The case-crossover design: a method for studying transient effects on the risk of acute events. Am J Epidemiol. 1991;133(2):144-53.

18. Tian L, Qiu H, Sun S, Tsang H, Chan KP, Leung WK. Association between emergency admission for peptic ulcer bleeding and air pollution: a case- crossover analysis in Hong Kong's elderly population. Lancet Planetary Health. 2017;1(2):e74-81.

19. Kim Y, Ng CFS, Chung Y, Kim H, Honda Y, Guo YL, Lim YH, Chen BY, Page LA, Hashizume M. Air pollution and suicide in 10 cities in Northeast Asia: a time-stratified case-crossover analysis. Environ Health Perspect. 2018;126(3): 037002.

20. Dominici F, Sheppard L, Clyde M. Health effects of air pollution: a statistical review. Int Stat Rev. 2003;71(2):243-76.

21. Carracedo-Martinez E, Taracido M, Tobias A, Saez M, Figueiras A. Casecrossover analysis of air pollution health effects: a systematic review of methodology and application. Environ Health Persp. 2010;118(8):1173-82.

22. Lu Y, Symons JM, Geyh AS, Zeger SL. An approach to checking casecrossover analyses based on equivalence with time-series methods. Epidemiology. 2008;19(2):169-75.

23. Armstrong BG, Gasparrini A, Tobias A. Conditional Poisson models: a flexible alternative to conditional logistic case cross-over analysis. BMC Med Res Methodol. 2014;14:122

24. Guo Y, Barnett AG, Pan X, Yu W, Tong S. The impact of temperature on mortality in Tianjin, China: a case-crossover design with a distributed lag nonlinear model. Environ Health Perspect. 2011;119(12):1719-25.

25. Li T, Yan M, Sun Q, Anderson GB. Mortality risks from a spectrum of causes associated with wide-ranging exposure to fine particulate matter: a casecrossover study in Beijing, China. Environ Int. 2018;111:52-9.

26. Luo YX, Li HB, Huang FF, Van Halm-Lutterodt N, Xu Q, Wang AX, Guo J, Tao LX, Li X, Liu MY, et al. The cold effect of ambient temperature on ischemic and hemorrhagic stroke hospital admissions: a large database study in Beijing, China between years 2013 and 2014-utilizing a distributed lag nonlinear analysis. Environ Pollut. 2018;232:90-6.

27. Tao Y, Zhong L, Huang X, Lu SE, Li Y, Dai L, Zhang Y, Zhu T, Huang W. Acute mortality effects of carbon monoxide in the Pearl River Delta of China. Sci Total Environ. 2011;410-411:34-40.

28. Harvey DI, Leybourne SJ. Testing for time series linearity. Economet J. 2007; 10(1):149-65.

29. Jolliffe IT, Cadima J. Principal component analysis: a review and recent developments. Philos Trans A Math Phys Eng Sci. 2016;374(2065):20150202.

30. Yang Y, Li RK, Li WJ, Wang M, Cao Y, Wu ZL, Xu Q. The association between ambient air pollution and daily mortality in Beijing after the 2008 Olympics: a time series study. PLoS One. 2013:8(10):e76759.

31. Altman DG, Bland JM. Statistics notes - interaction revisited: the difference between two estimates. Brit Med J. 2003;326(7382) 219-219.

32. Ballester F, Tenias JM, Perez-Hoyos S. Air pollution and emergency hospital admissions for cardiovascular diseases in Valencia, Spain. J Epidemiol Community Health. 2001;55(1):57-65.

33. Barnett AG, Williams GM, Schwartz J, Best TL, Neller AH, Petroeschevsky AL, Simpson RW. The effects of air pollution on hospitalizations for cardiovascular disease in elderly people in Australian and New Zealand cities. Environ Health Persp. 2006;114(7):1018-23.

34. Samoli E, Touloumi G, Schwartz J, Anderson HR, Schindler C, Forsberg B, Vigotti MA, Vonk J, Kosnik M, Skorkovsky J, et al. Short-term effects of carbon monoxide on mortality: an analysis within the APHEA project. Environ Health Persp. 2007;115(11):1578-83.

35. Liu H, Tian Y, Xiang X, Sun K, Juan J, Song J, Cao Y, Xu B, Hu Y. Air pollution and hospitalization for acute myocardial infarction in China. Am J Cardiol. 2017; 120(5):753-8

36. Li W, Cao Y, Li R, Ma X, Chen J, Wu Z, Xu Q. The spatial variation in the effects of air pollution on cardiovascular mortality in Beijing, China. J Expo Sci Environ Epidemiol. 2018;28(3):297-304.

37. Brook RD, Franklin B, Cascio W, Hong Y, Howard G, Lipsett M, Luepker R, Mittleman M, Samet J, Smith SC Jr, et al. Air pollution and cardiovascular disease: a statement for healthcare professionals from the expert panel on population and prevention science of the American Heart Association. Circulation. 2004;109(21):2655-71.

38. Bourdrel T, Bind MA, Bejot Y, Morel O, Argacha JF. Cardiovascular effects of air pollution. Arch Cardiovasc Dis. 2017:110(11):634-42.

39. Shao QM, Liu T, Korantzopoulos P, Zhang ZW, Zhao JP, Li GP. Association between air pollution and development of atrial fibrillation: a meta-analysis of observational studies. Heart Lung. 2016;45(6):557-62.

40. Rich DQ, Mittleman MA, Link MS, Schwartz J, Luttmann-Gibson H, Catalano PJ, Speizer FE, Gold DR, Dockery DW. Increased risk of paroxysmal atrial fibrillation episodes associated with acute increases in ambient air pollution. Environ Health Perspect. 2006;114(1):120-3. 
41. Shah AS, Langrish JP, Nair H, MCAllister DA, Hunter AL, Donaldson K, Newby $\mathrm{DE}$, Mills NL. Global association of air pollution and heart failure: a systematic review and meta-analysis. Lancet. 2013;382(9897):1039-48.

42. Liu H, Tian Y, Song J, Cao Y, Xiang X, Huang C, Li M, Hu Y. Effect of ambient air pollution on hospitalization for heart failure in 26 of China's largest cities. Am J Cardiol. 2018;121(5):628-33.

43. Li Y, Wu YF, Chen KP, Li X, Zhang X, Xie GQ, Wang FZ, Zhang S. Prevalence of atrial fibrillation in China and its risk factors. Biomed Environ Sci. 2013; 26(9):709-16.

44. Gu D, Huang G, He JJCJoC: Investigation of prevalence and distributing feature of chronic heart failure in Chinese adult population. 2003, 31:3-6

45. Zhang J. Low-level air pollution associated with death: policy and clinical implications. JAMA. 2017;318(24):2431-2.

46. Chen R, Pan G, Kan H, Tan J, Song W, Wu Z, Xu X, Xu Q, Jiang C, Chen B. Ambient air pollution and daily mortality in Anshan, China: a time-stratified case-crossover analysis. Sci Total Environ. 2010;408(24):6086-91.

47. Son JY, Lee JT, Kim H, Yi O, Bell ML. Susceptibility to air pollution effects on mortality in Seoul, Korea: a case-crossover analysis of individual-level effect modifiers. J Expo Sci Environ Epidemiol. 2012;22(3):227-34.

48. Lee FY, Chen WK, Lin CL, Kao CH. Carbon monoxide poisoning and subsequent cardiovascular disease risk: a nationwide population-based cohort study. Medicine (Baltimore). 2015;94(10):e624

49. Lee IM, Tsai SS, Ho CK, Chiu HF, Wu TN, Yang CY. Air pollution and hospital admissions for congestive heart failure: are there potentially sensitive groups? Environ Res. 2008;108(3):348-53.

50. McGrath JJ. Biological plausibility for carbon monoxide as a copollutant in PM epidemiologic studies. Inhal Toxicol. 2000;12:91-107.

51. Wu PE, Juurlink DN. Carbon monoxide poisoning. CMAJ. 2014;186(8):611.

52. Andre L, Boissiere J, Reboul C, Perrier R, Zalvidea S, Meyer G, Thireau J, Tanguy S, Bideaux P, Hayot M, et al. Carbon monoxide pollution promotes cardiac remodeling and ventricular arrhythmia in healthy rats. Am J Respir Crit Care Med. 2010;181(6):587-95.

53. Satran D, Henry CR, Adkinson C, Nicholson Cl, Bracha Y, Henry TD. Cardiovascular manifestations of moderate to severe carbon monoxide poisoning. J Am Coll Cardiol. 2005;45(9):1513-6.

54. Wu X, Basu R, Malig B, Broadwin R, Ebisu K, Gold EB, Qi LH, Derby C, Green RS. Association between gaseous air pollutants and inflammatory, hemostatic and lipid markers in a cohort of midlife women. Environ Int. 2017:107:131-9.

55. Chen SY, Chan CC, Su TC. Particulate and gaseous pollutants on inflammation, thrombosis, and autonomic imbalance in subjects at risk for cardiovascular disease. Environ Pollut. 2017;223:403-8.

56. Reboul C, Boissiere J, Andre L, Meyer G, Bideaux P, Fouret G, Feillet-Coudray C, Obert P, Lacampagne A, Thireau J, et al. Carbon monoxide pollution aggravates ischemic heart failure through oxidative stress pathway. Sci Rep. 2017;7:39715.

57. Rose JJ, Wang L, Xu QZ, MCTiernan CF, Shiva S, Tejero J, Gladwin MT. Carbon monoxide poisoning: pathogenesis, management, and future directions of therapy. Am J Resp Crit Care. 2017;195(5):596-606.

Ready to submit your research? Choose BMC and benefit from:

- fast, convenient online submission

- thorough peer review by experienced researchers in your field

- rapid publication on acceptance

- support for research data, including large and complex data types

- gold Open Access which fosters wider collaboration and increased citations

- maximum visibility for your research: over $100 \mathrm{M}$ website views per year

At BMC, research is always in progress.

Learn more biomedcentral.com/submissions 